University of Nebraska - Lincoln

DigitalCommons@University of Nebraska - Lincoln

\title{
Monitoring gradual ecosystem change using Landsat time series analyses: Case studies in selected forest and rangeland ecosystems
}

James E. Vogelmann

U.S. Geological Survey, vogel@usgs.gov

George Xian

ASRC Research and Technology Solutions

Collin Homer

U.S. Geological Survey, homer@usgs.gov

Brian Tolk

Stinger Ghaffarian Technologies

Follow this and additional works at: https://digitalcommons.unl.edu/usgsstaffpub

Vogelmann, James E.; Xian, George; Homer, Collin; and Tolk, Brian, "Monitoring gradual ecosystem change using Landsat time series analyses: Case studies in selected forest and rangeland ecosystems" (2012). USGS Staff -- Published Research. 528.

https://digitalcommons.unl.edu/usgsstaffpub/528

This Article is brought to you for free and open access by the US Geological Survey at DigitalCommons@University of Nebraska - Lincoln. It has been accepted for inclusion in USGS Staff -- Published Research by an authorized administrator of DigitalCommons@University of Nebraska - Lincoln. 


\title{
Monitoring gradual ecosystem change using Landsat time series analyses: Case studies in selected forest and rangeland ecosystems
}

\author{
James E. Vogelmann ${ }^{\mathrm{a}, *}$, George Xian ${ }^{\mathrm{b}}$, Collin Homer ${ }^{\mathrm{a}}$, Brian Tolk ${ }^{\mathrm{c}}$ \\ a U.S. Geological Survey (USGS), Earth Resources Observation and Science (EROS) Center, Sioux Falls, SD 57198, USA \\ b ASRC Research and Technology Solutions (ARTS), 6303 Ivy Lane, Suite 130, Greenbelt, MD 20770, USA \\ c Stinger Ghaffarian Technologies (SGT), 7701 Greenbelt Road, Suite 400, Greenbelt, MD 20770, USA
}

\section{A R T I C L E I N F O}

Available online 9 February 2012

\section{Keywords:}

Landsat time series

Ecosystem trends

Forest decline

Forest expansion

Sagebrush loss

\begin{abstract}
A B S T R A C T
The focus of the study was to assess gradual changes occurring throughout a range of natural ecosystems using decadal Landsat Thematic Mapper (TM) and Enhanced Thematic Mapper Plus (ETM +) time series data. Time series data stacks were generated for four study areas: (1) a four scene area dominated by forest and rangeland ecosystems in the southwestern United States, (2) a sagebrush-dominated rangeland in Wyoming, (3) woodland adjacent to prairie in northwestern Nebraska, and (4) a forested area in the White Mountains of New Hampshire. Through analyses of time series data, we found evidence of gradual systematic change in many of the natural vegetation communities in all four areas. Many of the conifer forests in the southwestern US are showing declines related to insects and drought, but very few are showing evidence of improving conditions or increased greenness. Sagebrush communities are showing decreases in greenness related to fire, mining, and probably drought, but very few of these communities are showing evidence of increased greenness or improving conditions. In Nebraska, forest communities are showing local expansion and increased canopy densification in the prairie-woodland interface, and in the White Mountains high elevation understory conifers are showing range increases towards lower elevations. The trends detected are not obvious through casual inspection of the Landsat images. Analyses of time series data using many scenes and covering multiple years are required in order to develop better impressions and representations of the changing ecosystem patterns and trends that are occurring. The approach described in this paper demonstrates that Landsat time series data can be used operationally for assessing gradual ecosystem change across large areas. Local knowledge and available ancillary data are required in order to fully understand the nature of these trends.
\end{abstract}

Published by Elsevier Inc.

\section{Introduction}

The Earth's natural vegetation is constantly changing (Manning et al., 2009). In some cases these changes are anthropogenic in nature, while in others the changes are in response to natural events. Natural resource managers, global change scientists, policy makers and researchers need more precise and synoptic information regarding types and trends of land cover. Such information has applications for assessing global carbon budgets, predicting fire behavior, understanding biodiversity, and hydrologic modeling (GEO, 2005). There is much demand for current land-cover information covering large areas, implying that change information should be updated at frequent time intervals. The Landsat Thematic Mapper (TM) and Enhanced Thematic Mapper Plus $(\mathrm{ETM}+)$ sensors are particularly appropriate for providing the imagery used to generate change information for assessing and monitoring natural resources. Landsat TM and ETM + data sets have

\footnotetext{
* Corresponding author at: USGS, Earth Resources Observation and Science (EROS) Center, Sioux Falls, SD 57198, USA. Tel.: + 16055946062.

E-mail address: vogel@usgs.gov (J.E. Vogelmann).
}

spatial, spectral and radiometric qualities that are especially well suited for ecological characterization (Wulder et al., 2008). In addition, TM and $\mathrm{ETM}+$ data have been systematically acquired for many portions of the globe since the launch of Landsat 5 in 1984, and thus a rich archive is available for analysis.

From the standpoint of mapping and monitoring landscape change using remotely sensed data, there are four general categories of vegetative changes: (1) abrupt change, (2) seasonal change, (3) gradual ecosystem change, and (4) short-term inconsequential change. The first three changes were recognized by Verbesselt et al. (2010), and in general, are the ones of most interest to most investigators. The fourth category, while not usually of major interest to most scientists and managers, includes the spectral changes that occur in response to a number of ephemeral weather-related factors. These spectral changes can hinder our interpretations of the first three types of ecosystem changes. All four types of changes can alter vegetative spectral properties, and depending on the goals of the investigation, can necessitate the use of different approaches and ancillary data to map them effectively. Each of these types of change will be described in further detail below. 
Abrupt changes are the result of changes caused by landscapetransforming disturbance events, such as those related to logging, deforestation, agricultural expansion, urbanization, and fire. In general, these types of events radically alter the spectral properties of the land surface, and are readily discernible in Landsat imagery. The literature is replete with examples of mapping and monitoring major disruptive changes using remotely sensed data (Clark and Bobbe, 2006; Coppin et al., 2004; Hansen et al., 2008; Hepinstall-Cymerman et al., 2009; Masek et al., 2008; Wulder et al., 2009). Challenges to mapping and monitoring these events often revolve around developing consistent, efficient and operational approaches to enable accurate characterization of these events (Brink and Eva, 2009; Huang et al., 2010a; Kennedy et al., 2010).

Seasonal change relates to the cyclical intra- and inter-annual patterns of phenology, whereby seasonality influences vegetation condition in predictable and mostly repeatable patterns of "green-up" and senescence. Similar to abrupt change, phenological change can have marked impacts on spectral characteristics of the vegetation, and tend to be especially pronounced in grasslands and deciduous forest. Phenology can also confound our ability to map and monitor many of the changes that natural resource managers are interested in characterizing. It is typical of many change investigations that steps be taken to temper the influence of phenology on final results. This requires a thorough understanding of the spectral patterns associated with phenology for the various types of vegetation in the area being investigated. Most phenological studies employing remotely sensed data require multiple observations during the growing season, and therefore trend towards sensors with high temporal frequency data, albeit with relatively low spatial resolution, such as the Advanced Very High Resolution Radiometer (AVHRR) or Moderate Resolution Imaging Spectrometer (MODIS) (Ganguly et al., 2010; Reed et al., 1994; White et al., 2009). While there are some cases whereby Landsat data have been successfully used to assess vegetative phenological status within a growing season (Gasparri et al., 2010; Vogelmann and DeFelice, 2003), Landsat is not the ideal sensor for such investigations due to the difficulty in acquiring enough quality cloud-free data sets to adequately characterize the phenological variability within an ecosystem. Nonetheless, Landsat data provide useful complementary data when used in conjunction with the high temporal resolution data in phenological assessments (Fisher and Mustard, 2007).

Gradual ecosystem change relates to subtle "within-state" changes taking place in vegetation communities that are not related to normal phenological cycles. These include a variety of withinstate disturbances, such as vegetation damage caused by insects and disease, drought and storms, changes in plant communities related to natural succession, grazing pressure, and climate-induced "biome shifts". While not receiving as much research in the Landsat community as abrupt-change research does, there have been a number of studies whereby these types of changes have been investigated (Beck et al., 2007; Kennedy et al., 2007, 2010; McDonald et al., 2007; Roder et al., 2008; Souza and Roberts, 2005; Vogelmann et al., 2009). Similar to abrupt change events, the cumulative impacts of gradual ecosystem changes can have substantial impacts on various ecosystem processes and result in changes in carbon balance and biogeochemical cycling, microclimate, and patterns of biodiversity (Lovett et al., 2006; Perry and Millington, 2007; Turner, 2005).

While not generally considered an important change from an ecological standpoint, short-term inconsequential vegetative change is a catch-all for a number of events that cause vegetative spectral changes not perceived as having long-term ecological importance. These include rain-fall events that affect spectral properties of the soil background (Fuller and Ottke, 2002), wind that affects leaf angles during the time of data acquisition (Lord et al., 1985), and light frost or snow on conifer vegetation at high elevations, occurring especially during the beginning and end of the growing season. These events may be considered "noise" by most analysts as they can have marked impacts on the spectral properties of the data sets being analyzed, which can in turn alter interpretations and create a level of uncertainty in remotely-sensed data sets and derived change products. These types of changes tend to be difficult to characterize, and are largely ignored in most change investigations.

This paper focuses on gradual ecosystem change. In this study, gradual change refers to increases or decreases in vegetation canopy cover occurring over an approximately two-decade time interval. In general, these changes in vegetation canopy cover relate to increases or decreases in the amount of greenness (or leaf area) detected by the Landsat sensors. Specifically, we use trend analysis using vegetation indices generated from multiple images or time series of Landsat $\mathrm{TM}$ and ETM + imagery to investigate the canopy cover changes for different ecological regimes located in four distinct regions of the US. As part of this study, we provide information regarding the characteristics of the gradual changes taking place across various landscapes. We believe that this type of information provides insight regarding the locations of the gradual ecosystem changes, the magnitude of the changes, and the vegetation communities impacted, as well as potential causes of the changes themselves. It is our intention to demonstrate that long-term trend analysis using Landsat data has value to the natural resource community, and that it is straightforward to operationally detect and monitor gradual landscape changes using Landsat time series data. We state upfront that we do not always have specific explanations regarding the causes of the changes that are occurring, but hope that this paper can help foster additional research and follow-on investigations in these and other areas.

\section{Study locations}

Four study areas representing a range of ecosystems were selected for this investigation (Fig. 1). Each area is characterized by different types of long term changes and agents of change. The areas selected include the following: (A) an arid area including both forests and rangeland in the southwestern US; (B) a sagebrush-dominated area in Wyoming; (C) a forested area adjacent to shortgrass prairie along the Niobrara River Valley in Nebraska, and (D) a forested highelevation area in the White Mountains of New Hampshire. These are described in further detail below.

\subsection{Southwestern US study site}

This area includes northwestern New Mexico and adjacent areas in Colorado, Utah and Arizona. The area is covered by four Landsat scenes, and includes forests and rangelands. The entire region has experienced severe drought during the past decade (Cook et al., 2004; National Drought Mitigation Center, 2011). In conjunction with the drought, the forests throughout the region have been adversely affected by a number of species of insects including the western spruce budworm (Choristoneura occidentalis) and spruce beetle (Dendroctonus rufipennis). The budworm is a defoliator, whereas the spruce beetle is a borer. Both have caused extensive forest damage in the southwestern US (Fellin and Dewey, 1982; Hayes and Lundquist, 2009). The combination of insect damage and drought throughout the southwestern US has resulted in widespread mortality in a number of tree species, including ponderosa pine (Pinus ponderosa), quaking aspen (Populus tremuloides), and pinyon pine (Pinus edulis) (Gitlin et al., 2006). Throughout much of the southwestern US, it has been estimated that over $90 \%$ of mature pinyon pine individuals have died across large areas at lower elevations (Breshears et al., 2005). Similarly, drought in conjunction with other factors such as insects and fungi is impacting many aspen stands in the southwestern US as well (Worrall et al., 2008).

This portion of the study represents a regional expansion of an initial localized prototype effort that we previously conducted in the San Pedro Wilderness area in northern New Mexico (Vogelmann et al., 


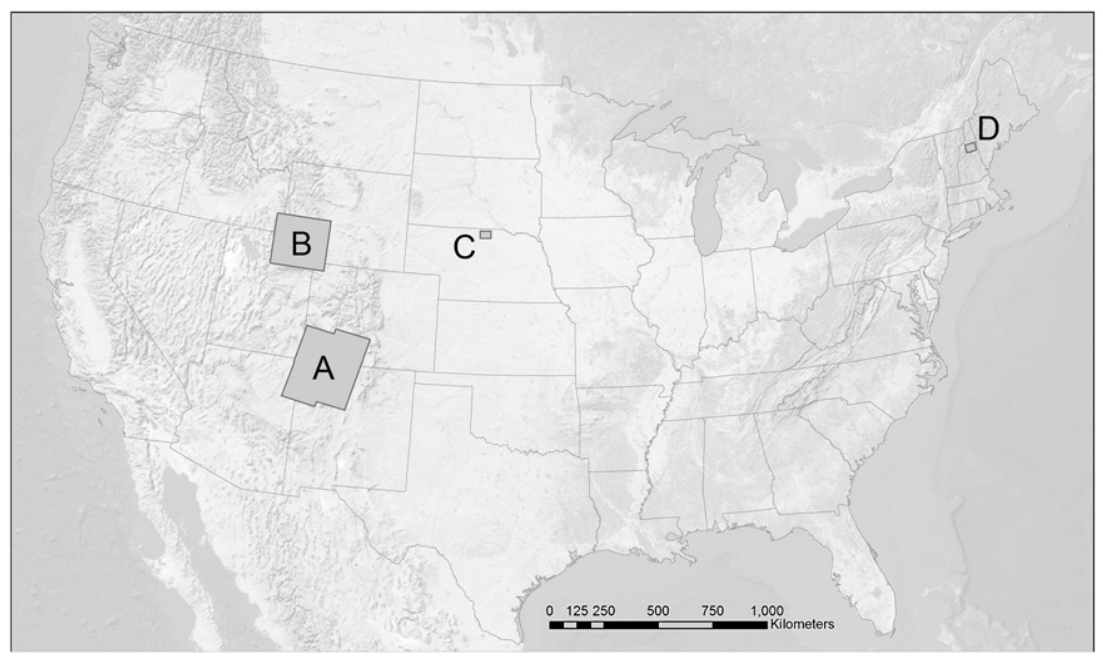

Fig. 1. Locations of the four test areas used in this study.

2009). The study region also includes an area of pinyon-juniper dieback investigated by Huang et al. (2010b) using Landsat data. For this study area, we were primarily interested in investigating changes in forest condition related to insect defoliation and/or drought. We were also interested in determining if there was any evidence for gradual changes occurring in the rangeland ecosystems. The insect damage and drought changes that we anticipated were expected to have decreased greenness and canopy cover.

\subsection{Wyoming sagebrush site}

This study area, which encompasses one Landsat scene, is located primarily in southwestern Wyoming. It lies predominately within the Wyoming Basin ecoregion, which is a broad and intermontane basin dominated by grasslands and shrublands (Griffith and Omernik, 2009). The study area includes a dry high hilly plateau region that is nearly surrounded by mountain ranges. Much of the area is dominated by a wide range of sagebrush steppe habitats, with Wyoming big sagebrush (Artemisia tridentata ssp. Wyomingensis) being the most common shrub. Mixed conifers are located at the higher elevations in the mountains. The climate is typical of semiarid and high plains ecosystems and precipitation varies a great deal across the area. Land cover changes having occurred throughout the region during the past several decades include those induced by drought, fire, mining, and oil and gas extraction. A large percentage of the land is publicly owned, with much of the rangelands being managed by the US Bureau of Land Management and the higher-elevation forested areas managed by the US Forest Service. For this study area, we were primarily interested in investigating changes in sagebrush communities related to drought and other types of disturbance. We were also interested in determining if there was evidence of gradual forest canopy cover changes in the higher elevation conifer forests. The rangeland and forest changes that we anticipated were expected to have resulted in decreased greenness and canopy cover.

\subsection{Niobrara River Valley Nebraska site}

The Niobrara River Valley is located in the north-central portion of Nebraska and is an area located within the Niobrara River Breaks ecoregion, which contains a mixture of grass species and woody vegetation common in the central hardwoods, northern hardwoods, and Rocky Mountain forests (Griffith and Omernik, 2008). Dominant tree species of the area include ponderosa pine, bur oak (Quercus macrocarpa), quaking aspen and bigtooth aspen (Quercus grandidentata). More detailed information about the vegetation of the Niobrara River Valley site is provided by Kaul et al. (1988). It should also be noted that a number of the dominant tree species of the region are at the edges of their range distributions, and as such are likely to be especially sensitive to climate variables such as moisture (Bloise et al., 2002). While not specifically documented for the Niobrara River Valley area, nearby locations have experienced the spread of ponderosa pine, presumably due to fire suppression (Steinauer and Bragg, 1987). It has also been reported that eastern red cedar (Juniperus virginiana) has expanded its range throughout the region (Frost and Powell, 2011). Our reason for selecting this site was to determine if there was evidence of forest range or density changes discernible through Landsat time series analysis. For this study area, we expected that the increased forest range and density changes would increase greenness and canopy cover. We expected that the spectral contrast between green forest vegetation and senescent prairie vegetation, which is often evident in late summer and early autumn, would facilitate our detection of forest trends. Thus we concentrated on late summer/early autumn Landsat imagery for this portion of the study.

\subsection{White Mountains New Hampshire site}

This site, located in the northern portion of New Hampshire, includes a number of mountains including Mt. Washington. The area has high topographic relief and the vegetation of the region is characterized by marked altitudinal zonation (Cogbill and White, 1991; Foster and Reiners, 1983). Deciduous tree species such as sugar maple (Acer saccharum), American beech (Fagus grandifolia), and yellow birch (Betula alleghaniensis) are the dominant forest species at the lowest elevations, paper birch (Betula papyrifera) is common at the mid-elevations, and the higher elevations are dominated by balsam fir (Abies balsamea), paper birch, and to a lesser extent red spruce (Picea rubens). The interface zones between deciduous and coniferous forest provide excellent sites for seeking evidence for shifts in forest distribution in response to climate change (Goldblum and Rigg, 2010). This is in part because the elevation changes are accompanied by steep climatic gradients, which in turn affect the distinct boundaries between vegetation types. Breckage et al. (2009) noted that in the Green Mountains of Vermont, which are floristically very similar to the White Mountains, lowland deciduous tree species expanded their ranges up the mountains between 1964 and 2004, presumably due to climate warming. Our goal with the White Mountains study site was to assess whether there was evidence of a similar biome shift by concentrating on distribution changes in the conifer component of these forests. The entire northeastern US is typically very cloudy, and the area we selected is contained in the overlap region 
of two adjacent World Reference System path/rows, which essentially doubles the number of scenes available for analysis. Most of the study region, and all of the higher elevations of the White Mountain study site, are within the White Mountains National Forest.

For this study area, we were most interested in determining if there was evidence for conifer forest expansion. Conifer vegetation in this region, of which the dominant montane species is balsam fir, occurs as dominant upper story forest vegetation at the higher elevations. Balsam fir is also a shade tolerant species, and occurs in the understory at middle elevations, where deciduous trees (mostly paper birch) are the dominant overstory forest vegetation. If overstory deciduous species such as paper birch decline, the balsam fir can replace the deciduous trees in the upper canopy (Burns and Honkala, 1965).

When deciduous trees are in the leaf-off state, the understory conifer vegetation is very discernible in Landsat imagery, and thus we chose leaf-off (spring) data as our primary source of remotely sensed data for trend analysis. For this study area, we anticipated that conifer forest would be decreasing due to deciduous forest encroachment, and thus we expected decreases in greenness and conifer forest canopy cover in the spring data. Later in the investigation, it became clear that additional information regarding summer conditions would help us interpret some of the results that we were observing in the leaf-off data, so we added an analysis of a leaf-on stack to assess birch overstory canopy conditions where conifer vegetation was occurring in the understory.

\section{Data and methods}

\subsection{Landsat data sets used}

For the southwestern US study site, 48 Landsat TM and ETM + scenes representing four WRS 2 Path/Rows (34/34, 34/35, 35/34 and 35/35; 1990 through 2010) were used. Fourteen Landsat TM scenes (Path/Row 37/31; 1988-2006) were acquired over the Wyoming sagebrush site, sixteen scenes (Path/Row 31/30; 1988-2010) were obtained over the Niobrara River Valley Nebraska site, and 23 Landsat scenes (Path/Rows 12/29 and 13/29; 1987 through 2010) were obtained over the White Mountains New Hampshire site. All data from the southwestern US study site and the Niobrara River Valley site were acquired during late summer through the middle of autumn (September through October). Data from Wyoming were acquired from summer (May through September). The primary source of data analyzed from the White Mountains (ten scenes) was acquired during early spring (April and May), after the majority of snowmelt but before foliation of deciduous trees. A leaf-on time series data stack (thirteen images from August and early September from 1985 through 2010) was also analyzed for the White Mountains site.

For the western US study sites, all scenes were processed according to Multi-Resolution Land Characteristics (MRLC) consortium protocols (Homer et al., 2004). This included conversion of digital numbers to top-of-atmosphere reflectance using coefficients from Chander et al. (2009). While we recognize that it is preferable to work with atmospherically corrected data, if possible, we felt that the top-of-atmosphere corrections employed would be acceptable in this study for these sites. This is based in part on results from previous work, whereby top-of-atmosphere corrections of images in data stacks were found to work well for assessing gradual changes in a forest in New Mexico affected by the western spruce budworm (Vogelmann et al., 2009). In the current study, images from the western United States sites appeared reasonably clear based on visual inspection, and we checked stable non-vegetated targets (i.e., pseudoinvariant features; Schott et al., 1988) located within these western study areas to ensure that such sites were reasonably spectrally stable over the time period. We did not see any evidence of either upward or downward biases through time for these pseudo-invariant targets. An example of a pixel located in a bright non-vegetated barren area (located by viewing historical images in Google Earth) following correction to top-of-atmosphere reflectance for images in the data stack is shown in Fig. 2. For these western US sites, atmospheric corrections might have improved results, but considering the inherent interannual variability in ecological systems, as well as the presumed clarity of atmospheric conditions in these areas, we suspect that the improvements would have been modest.

In the case of the eastern US (White Mountains) site, we normalized the spring data sets to a base-line scene (corrected to top-of-atmosphere reflectance) using several bright and dark pseudo-invariant targets (Schott et al., 1988). We should note that the adjustments were very minor for all bands in all images. Summer data over the White Mountains were corrected to surface reflectance using a local implementation of the LEDAPS processing code (Masek et al., 2006). We felt that it was important to implement normalization/atmospheric correction for data from this site because atmospheric conditions can be expected to be highly variable throughout the region (as they tend to be throughout the rest of the entire eastern US). Consequently, atmospheric effects can be expected to have significant impact on the image radiometry throughout the study area.

\subsection{General methods and approach}

For each study area, we used the Normalized Difference Vegetation Index (NDVI) and/or the Short Wave Infrared/Near Infrared Index (SWIR/NIR) to assess trends. For this study, the NDVI was defined as (Band 4-Band 3)/(Band 4+Band 3), where Band 4 is reflectance of Landsat TM or ETM + Band 4, and Band 3 is reflectance of Landsat TM or ETM + Band 3. The NDVI is a standard "greenness" index that has been used for many applications, and has been shown to work well for detecting significant changes in levels of green vegetation (Coppin et al., 2004). The SWIR/NIR was defined as Band 5/Band 4, where Band 5 is reflectance of Landsat TM or ETM + Band 5 , and Band 4 is reflectance of Landsat TM or ETM + Band 4. The SWIR/NIR has been shown to be more sensitive than NDVI for detecting changes in leaf-on (summer) conifer canopies (Vogelmann, 1990; Vogelmann et al., 2009). Therefore, this index was the primary index used for assessing conifer forest trends in the southwestern US and the White Mountain New Hampshire (summer data) study areas. It was also used to assess forest status at Niobrara Nebraska. The NDVI index was the primary index used in Wyoming, Niobrara Nebraska, and the White Mountains New Hampshire (leaf-off data) study areas. We did not attempt to correct for any temporal variation in index values. While we recognize that timing and phenology can be important, correction for these factors was beyond the scope of the study.

Time-series data stacks were generated for each study area using the aforementioned indices. Clouds and snow were masked out

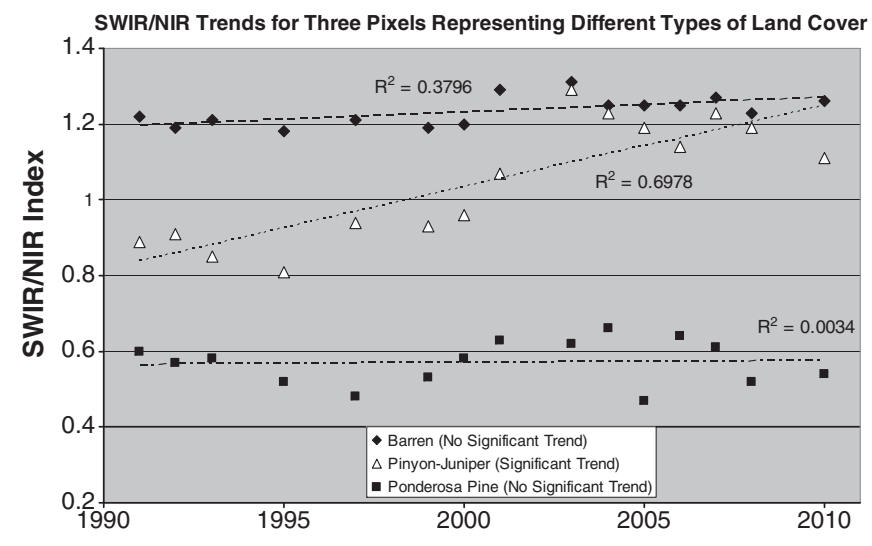

Fig. 2. Example of SWIR/NIR regression model trends for selected individual pixels representing different land cover types and conditions. This example is from the southwestern US study area. 
prior to the generation of the data stacks, so that only cloud-free and snow-free pixels were used in the analyses. Clouds and cloud shadows were masked using on-screen digitizing of the clouds and shadows visually apparent in the images. Actual areas delineated and masked out tended to be larger than the areas directly covered by the clouds and shadows, such that we had high confidence that the actual pixels used for trend analyses were not unduly impacted by clouds or shadows. Snow areas were masked out using a series of "quick alarms", whereby training areas in snow areas were selected (using Bands 5, 4 and 3), and pixels throughout the image that were spectrally similar to the training areas were isolated and masked out.

We then generated linear regression relationships on a pixel by pixel basis between time ( $\mathrm{x}$ variable) and the vegetation index value (y variable) for selected pixels (Fig. 2). As a general rule, regression models with low slope values tend not to be statistically significant (i.e. no apparent trend), whereas regression models with high positive or negative slope values are more likely to be statistically significant. To help visualize the significant trends spatially, a spatial model was developed whereby linear regressions of spectral index versus time were developed for each pixel in the image "stack" using all data sets for the study sites. Images depicting regression line slope, $t$ values, and probability values of statistical significance ( $p$ at $0.01,0.05$ and 0.10 levels of confidence) were derived. This approach was found to be effective for providing forest trend information in a high elevation conifer stand impacted by western spruce budworm (Vogelmann et al., 2009). In that study, it was shown that locations where $\mathrm{p}$ values are at 0.01 and 0.05 levels of confidence were particularly effective at depicting spatial trends, thus we adopted this approach for the current study.

For the Wyoming sagebrush study site, we conducted an additional analysis. For this area, we estimated the proportions of sagebrush for every $30 \mathrm{~m}$ pixel in 1988, 1996 and 2006. This was done using a combination of on-site field measurements, Quickbird (QB) satellite images, and Landsat images. Field measurements were made using a series of $1-\mathrm{m}^{2}$ quadrats along transects in pre-selected areas covered by the QB images. Information collected at each location included sagebrush cover from an overhead perspective, and the total cover for all vegetation and soil components.

On-site field measurements can directly be used to model percent sagebrush cover over large areas, such as across entire Landsat scenes, but only if there are enough field samples to enable the characterization of the many conditions that occur across the entire areas. Due to funding and time constraints, we found it difficult to obtain enough on-site samples to enable sagebrush canopy cover characterization at the required accuracy for the area covered by an entire Landsat scene. Therefore, we used QB images, which have a $16.5 \times 16.5 \mathrm{~km}$ scene size at nadir, as an intermediate step. We first derived relationships between field measurements and four QB images (all located within Path/Row 31/30) to estimate sagebrush cover for each $Q B$ scene area. Once generated, QB scale estimates were used to provide a large number of samples to be used as image-based training data for generating canopy characterizations across the extent of an entire Landsat scene.

Percent cover of sagebrush in 2006 was estimated first, and then percent cover of sagebrush was estimated for 1996, followed by 1988 . The 2006 estimate was done using a combination of $30 \mathrm{~m}$ spatial resolution $\mathrm{TM}$ images and $2.4 \mathrm{~m}$ resolution $\mathrm{QB}$ satellite images from the same year (Homer et al., 2012). Briefly, the on-site vegetation cover data were used as a training dataset with $\mathrm{QB}$ images to build regression tree models to depict percent sagebrush cover at 2.4-m resolution for the areas covered by the QB imagery. This information was then re-scaled to 30-m and used as training data with multiple-season Landsat and Digital Elevation Model data to build regression tree models to estimate the 2006 percent sagebrush cover for the entire study site (Homer et al., 2012). Landsat TM images for the three different years (2006, 1996, and 2006) were selected using imagery from mostly the same months to minimize seasonal differences and to obtain optimal normalizations. For each year, data were acquired from May, June and September (except for June 1996, when data were not available due to cloud cover). Image pairs of 2006-1996 and 1996-1988 were analyzed to identify change areas for the periods 2006-1996 and 1996-1988 through image change vector analysis (Xian and Homer, 2010; Xian et al., 2009). The change vector calculated the difference of all Landsat bands excluding the thermal band from the image pairs across each of the two time periods. The change vector was then partitioned into changed and unchanged components by using different thresholds. The 2006 base areas that were identified as unchanged from the 1996-2006 and 1988-1996 image pairs were then used as training datasets to create regression tree models for 1996 and 1988. The sagebrush percent cover in 1996 and 1988 was estimated separately for identified change areas from the 2006 base by using the regression models (Xian et al., 2012).

\subsection{Ancillary data}

Depending on the study site, we used a variety of ancillary data sets to help interpret the trends data. For the southwestern US, we used a $30 \mathrm{~m}$ vegetation classification data layer generated for the entire US by the LANDFIRE project (Rollins, 2009) to help interpret vegetation types. The LANDFIRE Vegetation Type data set is based on the Ecological Systems classification (Comer et al., 2003) developed by NatureServe. For this investigation, many of the legend classes from the LANDFIRE vegetation data set were collapsed into a limited number of cover classes to simplify comparison with the spectral trends information. The proportion of pixels with increasing or decreasing trends was calculated for each merged class to provide quantitative assessments of change as a function of vegetation type.

In addition, data from the Forest Health Monitoring (FHM) program (USDA, 2011) were used to help interpret trends data in the southwestern US. The FHM program is designed to determine the status, changes and trends of forest condition in the United States annually. Digital sketch map data sets used in the study were acquired from the southwestern US study site from 1998 through 2010 (one map data layer for each year). Individual data layers were combined to identify areas where forest damage was mapped most frequently through the years. In general, sketch mapping data provide good general depictions of where forest damage has occurred, and what the damage was caused by. We do not want to ascribe too much value to the precise locations of damaged areas depicted by a single sketch map data set, but rather are more interested in the overall patterns of damage, the repeatability of the patterns, and the type of damage.

Data from Google Earth (http://earth.google.com/) were used to help provide quantitative estimates of how much non-forest to forest change has been taking place in the Niobrara River Valley region. Four hundred points were randomly selected from this ecoregion, and were overlain onto the aerial photographs using Google Earth. Each point was assessed as to (1) if it was forest or non-forest for each date available in the Google Earth historical archive, and (2) if forested, whether it showed evidence of change from a non-forested to a forested state over the time period (generally from 1993 through 2009). From this information, we calculated the proportion of points that underwent transition from non-forested to forested states over the 1993-2009 timeframe. This timeframe is reasonably comparable to the 1988-2010 time frame used for the Landsat time series investigation.

\section{Results}

\subsection{Southwest US study area}

Comparison between the image composite and the spatial representation of overall SWIR/NIR trends from the southwestern US study site (Fig. 3) shows that most, although not all significant trends are located in the forested areas. Areas showing evidence of 

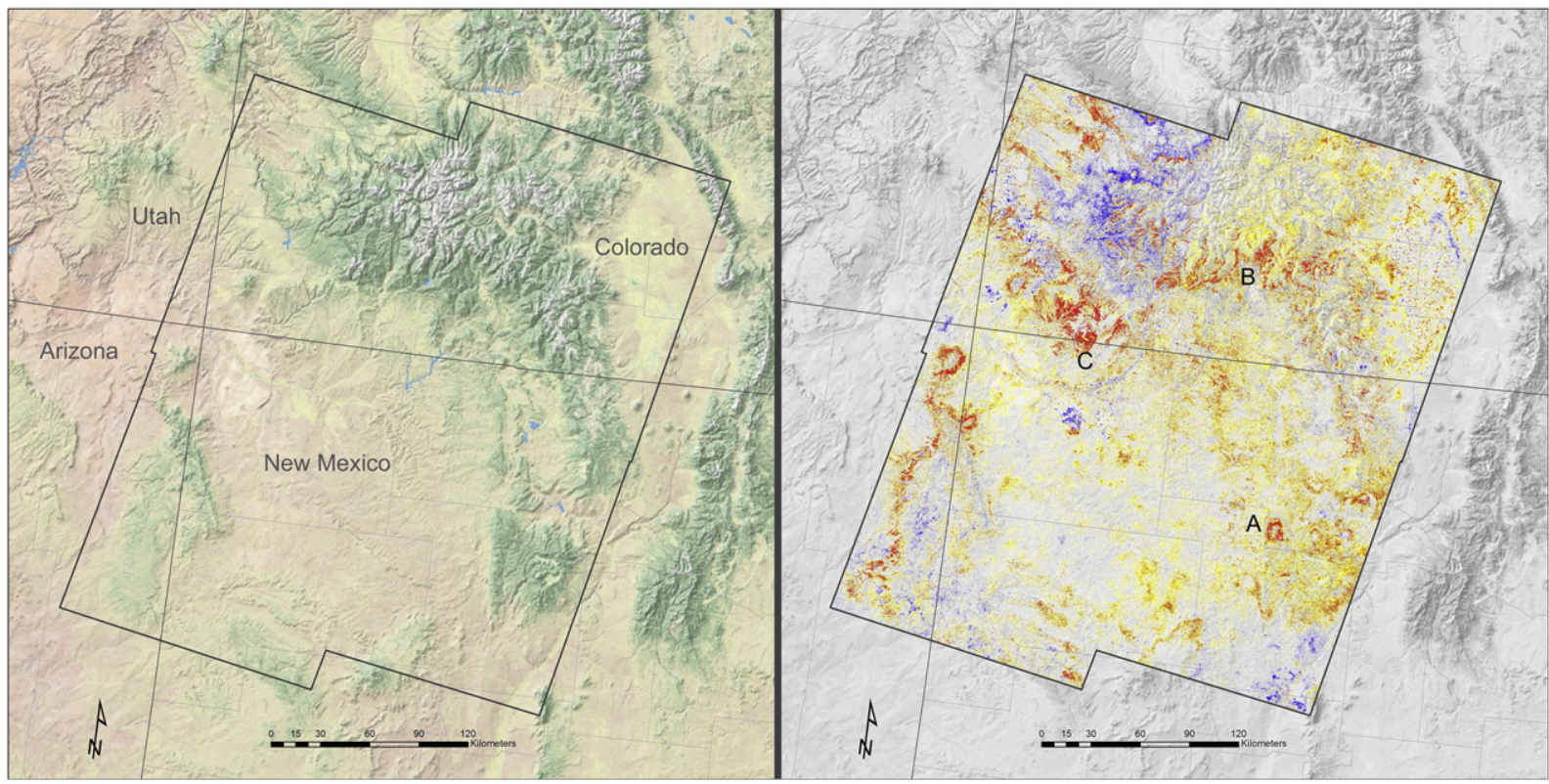

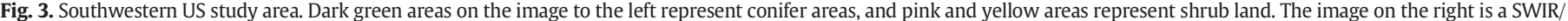

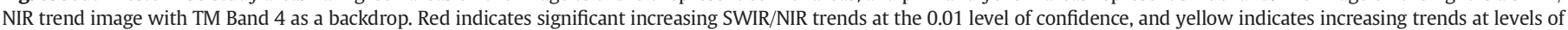

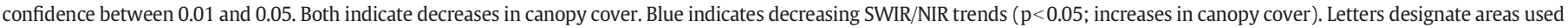
as close-ups in Fig. 4, and are discussed in further detail in text.

decreased green canopy cover (i.e. increases in SWIR/NIR) are red or yellow. Comparison with LANDFIRE vegetation classification data indicates that most of these areas are located in areas of mixed conifers, ponderosa pine and pinyon-juniper (Table 1). An area of blue, associated with deciduous trees, indicates where decreases in SWIR/NIR have occurred, implying increased canopy cover. While there are some areas in the rangelands that are showing various trends, these areas are relatively small and are localized, compared with the more widespread trends observed in the forest lands.

Close-ups of specific areas (Fig. 4) demonstrate the level of detail contained within the trend data sets. The left images are false color composites that can be used for interpretation and orientation purposes. Fig. 4A represents the trends in a high-elevation spruce-fir forest located in the San Pedro Peaks Wilderness area. This site, the focus of a previous Landsat time series study (Vogelmann et al., 2009), was shown by field visit to have experienced significant damage caused by the western spruce budworm. Comparison between Landsat time series trend images from the previous study (1990 through 2007 timeframe), and the current study (1990 through the 2010 timeframe) indicates that the zone of conifer damage expanded towards the top of the

Table 1

Summary of Landsat-derived time-series trends for different land cover types in the southwestern US study site. Trends are defined as those areas showing significant linear relationships between time and SWIR/NIR index value at the 0.05 level of confidence or higher.

\begin{tabular}{llll}
\hline Land cover type & Area $\left(\mathrm{km}^{2}\right)$ & \% Decreasing cover & \% Increasing cover \\
\hline Grasslands & 23,757 & 8.5 & 3.3 \\
Deciduous forest & 8346 & 12.5 & 8.7 \\
Pinyon-juniper & 27,767 & 21.1 & 1.6 \\
Ponderosa pine & 8641 & 16.5 & 3.7 \\
Mixed conifers; & 4422 & 25.9 & 2.0 \\
$\quad$ low elevation & & & 1.8 \\
Mixed conifers; & 5710 & 28.0 & 1.6 \\
$\quad$ high elevation & & 7.1 & \\
Shrubland & 23,958 & & \\
\hline
\end{tabular}

mountain from 2007 to 2010. The FHM program also identified this area as being damaged by budworm (Fig. 4A; right image). It can be seen that the areas of most intense red (i.e., multiple years of observations of insect damage) in the FHM data set correspond reasonably closely with the areas with 0.01 level confidence of increasing SWIR/ NIR trends (decreased cover) depicted by red.

Fig. 4B shows an area in Colorado where conifer damage caused by the spruce beetle is prevalent. The location of the areas showing decreasing canopy cover trends aligns similarly to what was mapped by the FHM program (USDA, 2011; Fig. 4B, right image). Fig. 4C shows an area where pinyon-juniper dieback has been extensive over the previous 20 years. This site, located near and within the Mesa Verde National Park, was also the primary location of an extensive ground and remote sensing investigation conducted by Huang et al. (2010b), where it was found that multi-temporal Landsat data could map carbon losses caused by the dieback related to severe and protracted drought. The trend images that we have generated for Fig. 4C have many similarities with the images developed by Huang et al. (2010b). The seam line seen in the FHM data for the site (lower right image) is related to the state line between Colorado and New Mexico. The FHM sketch mapping is done on a region by region basis, and Colorado and New Mexico are located in different USDA Forest Service mapping regions. Thus the sketch map composite shows differences in data mapping, interpretation and production between the two groups.

The proportion of areal extent showing either positive or negative SWIR/NIR trends varies according to land cover type (Table 1 ). The general land cover categories that had the greatest areal extents with decreasing forest cover (increased SWIR/NIR trends) were three conifer classes, with the higher elevation mixed conifers, lower elevation mixed conifers, and pinyon-juniper being adversely affected in the $21-28 \%$ range. About $12 \%$ of the deciduous forests showed decreasing canopy cover trends, and $7-8 \%$ of the shrublands and grasslands (the latter located mostly above timberline) showed decreasing canopy cover trends. With the exception of deciduous forest, none of the classes showed much evidence of increasing canopy cover trends (i.e. decreasing SWIR/NIR). 


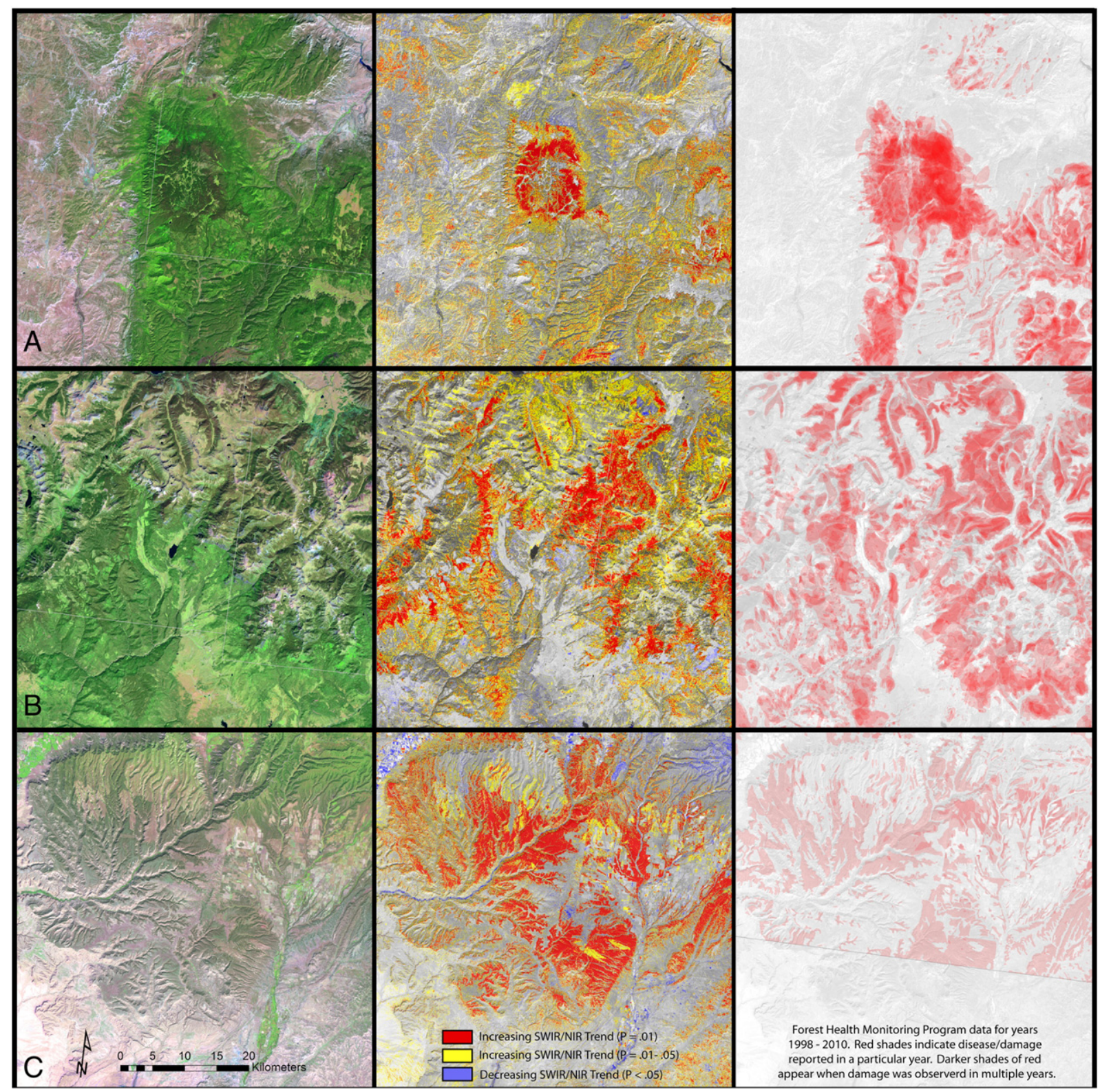

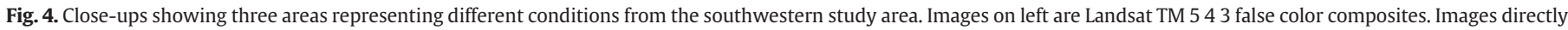

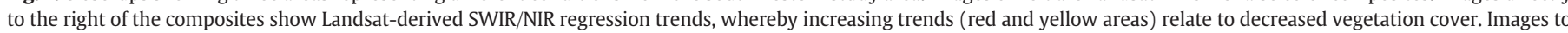

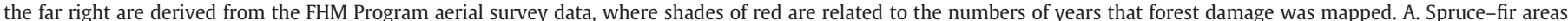
affected by the western spruce budworm. B. Spruce-fir areas impacted by the spruce beetle. C. Pinyon-juniper areas affected by severe and protracted drought.

\subsection{Wyoming study area}

Analysis of the NDVI trends from the Wyoming study area indicated that small pockets of sagebrush changed, with some areas showing trends of decreasing greenness and very few areas showing trends of increasing greenness. These areas were very small when compared with the areas showing trends in the higher-elevation conifer forests in the mountains located in the western portion of the scene. It is noteworthy that some of the conifer areas in this scene showed evidence of increasing greenness, whereas others showed evidence of decreasing greenness. Some of these areas appeared to be related to the location of previous wildland fires, as depicted by Monitoring Trends in Burn Severity data (MTBS, 2011). Assessments of change patches in sagebrush areas using multi-year data sets indicated that the largest reductions were related to wildland fire. Fig. 5 shows percent sagebrush in 1988(a), shrub changes from 1988 to 1996 (b), and shrub changes from 1996 to 2006 (c). Shrub cover decreases from 1988 to 1996 (indicated by red color areas) are more moderate than the decreases that occurred from 1996 to 2006. The sagebrush reductions resulting from fire disturbances can be seen in Fig. 5C in the southeastern corner of the area. Reductions in sagebrush in the northern portion of the study area (Fig. 5C) are related to oil and gas well developments. Overall, sagebrush had an aerial reduction of $31 \mathrm{~km}^{2}$ from 1988 to 2006 in the study area.

\subsection{Niobrara River Valley Nebraska study area}

The Landsat time-series trend image for the Niobrara River Valley site shows that areas of significant NDVI increases are diffusely scattered throughout the entire forest zone (Fig. 6). The patterns of increased greenness are such that increases in greenness at the 0.01 confidence level (orange) are interspersed with areas at the 0.05 levels 


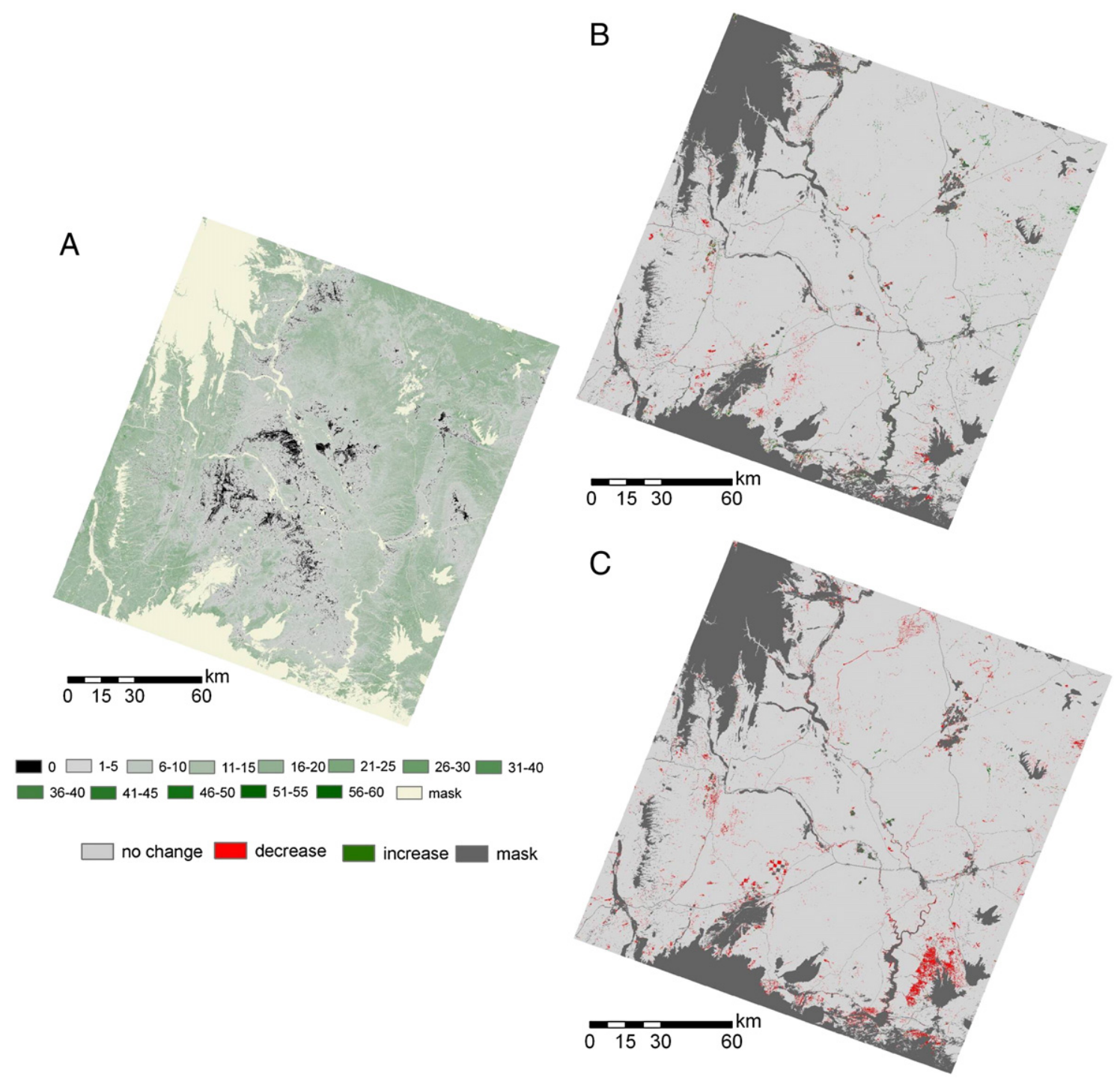

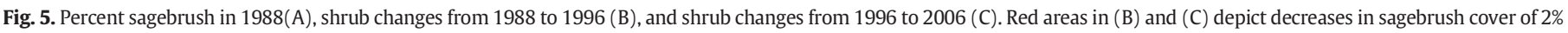

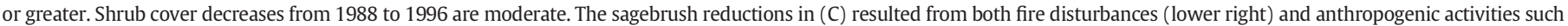
as natural gas extraction and mining.

of confidence (green). Neither occurs as cohesive units within the forested areas, implying that the greenness changes, while statistically significant, are not occurring homogeneously. It is also apparent that a number of center pivot agricultural areas are showing increased trends in greenness over the time (circular orange and green areas). Inspection of these areas in the original source imagery indicated that most of these changed center pivot areas were actually prairie during the earliest years (i.e., during the late 1980s and early 1990s), and that these prairie areas were converted to center pivots during the latter years (i.e., in the years just prior to and including 2010).

A Google Earth close-up view (Fig. 7) of the region depicted by the yellow area in Fig. 6 provides an indication of the nature of the forest increases. The arrows in the Fig. 7 indicate two areas where forest has increased markedly between 1993 and 2009. Approximately 33\% of the Niobrara River Breaks ecoregion was determined to be forest, based on the tabulation of the location of the 400 random points sampled from the Google Earth imagery. Of the forested points, about 21\% were found to have undergone land cover change from non-forest to forest between 1993 and 2009. This translates to an increase in forest area of approximately $7 \%$ of the entire ecoregion over the time frame. This compares with approximately $34.8 \%$ of the forested pixels showing statistically significant increases in NDVI (i.e., at the 0.05 level of confidence) over the
1988-2010 timeframe. Approximately $1.0 \%$ of the forested pixels showed decreasing trends in NDVI that were statistically significant.

\subsection{White Mountains New Hampshire study area}

Analysis of the leaf-off NDVI trends data from the White Mountains of New Hampshire (Fig. 8) indicates greenness is increasing throughout much of the forested areas in the region, especially in areas where the upper story is dominated by deciduous tree species. Because we are using data prior to deciduous forest green-up, we can conclude that the increase in greenness is attributable to increases in conifer vegetation, and that conifer vegetation is becoming more dominant in the deciduous sub-canopy towards the lower parts of the mountain slopes along an elevation gradient. The increase in greenness was not observed when using the leaf-on (summer) image stacks.

\section{Discussion}

\subsection{Ecological considerations; western sites}

It is apparent from this analysis that much of the conifer forest within the southwestern US is showing evidence of decreasing trends 


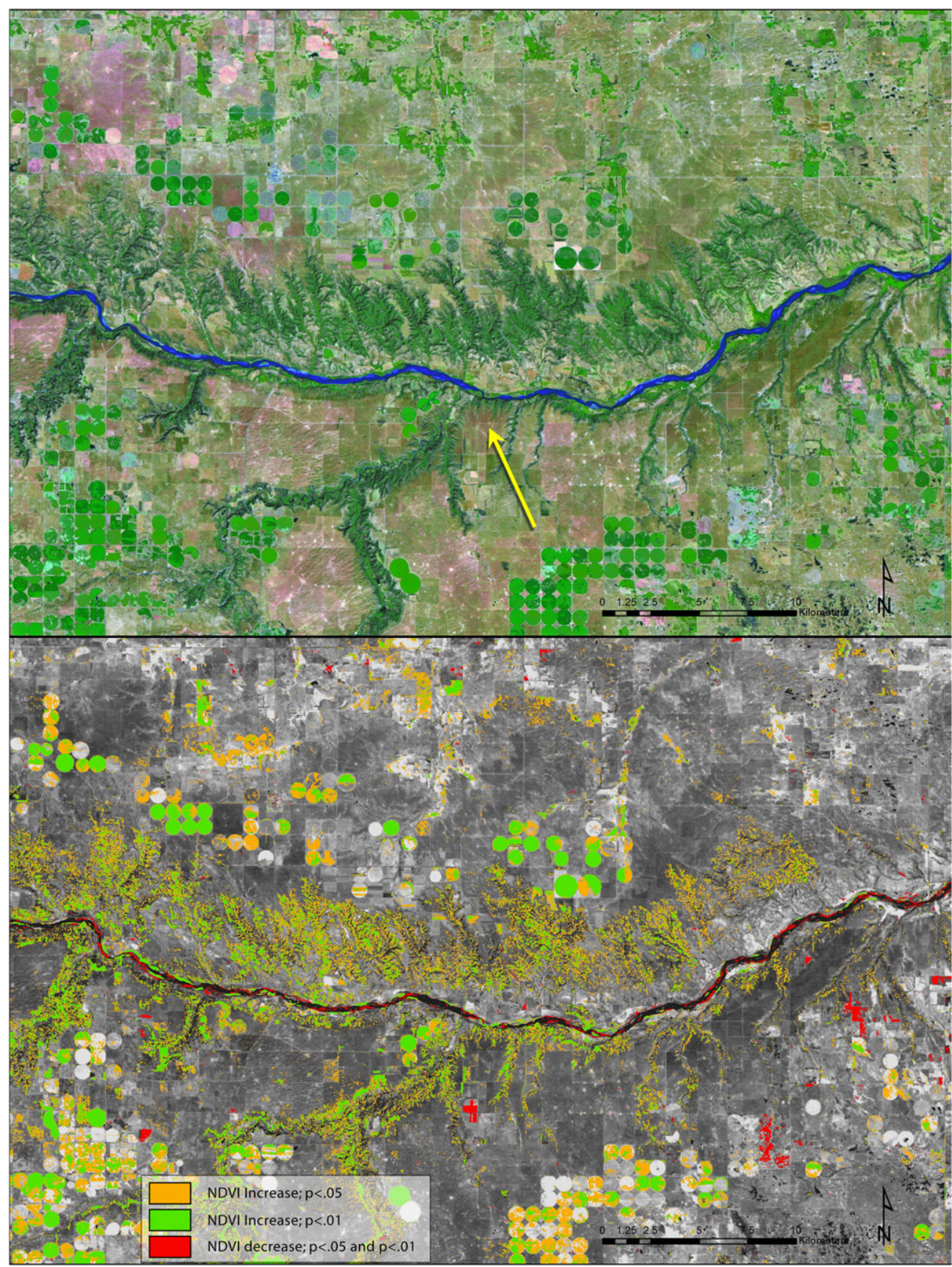

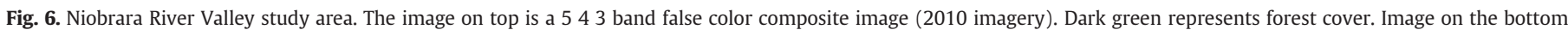

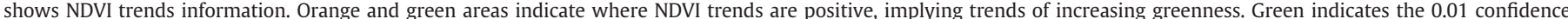

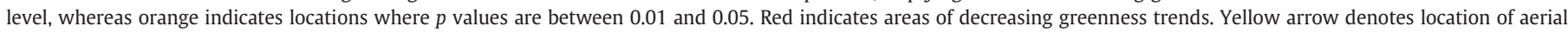
photographs shown in Fig. 7.

in canopy cover. Comparison with FHM data indicates that many of the zones of decreases in canopy cover are associated with areas of high tree mortality, and thus represent declining forest conditions. Many of these forests are located at the higher elevations of the region, although pinyon-juniper occurs at lower elevations. In the higher elevation conifer areas, declines are primarily related to insects, whereas in the case of pinyon-juniper, the decline is mostly related to long-term drought. Based upon climate data, it is likely that many of the higher elevation conifer areas showing evidence of decline have been experiencing drought conditions as well. There is often a relationship between insect damage and drought (Dale et al., 2001), and it is likely that drought has exacerbated the insect outbreaks. There were few conifer areas in the southwestern study site that showed evidence of increasing trends in canopy cover (i.e., decreasing SWIR/NIR trends). Analyses of NDVI trends also showed little evidence of increasing conifer greenness occurring in these forests. This is noteworthy in that many studies have implicated increases in forest biomass in response to fire suppression activities throughout much of the western US over the last several decades (Canadell et al., 2007; Houghton et al., 2000). This increase in biomass is often given as a partial reason explaining the increases in wildfire intensity during the past decade. Over the timeframe used in this study, we do not see evidence for increasing greenness in these conifer areas. We deduce that drought variables are likely to be having a greater impact on the wildfire fire events in this study area than increases in forest biomass. However, we should also note that we did see evidence of 


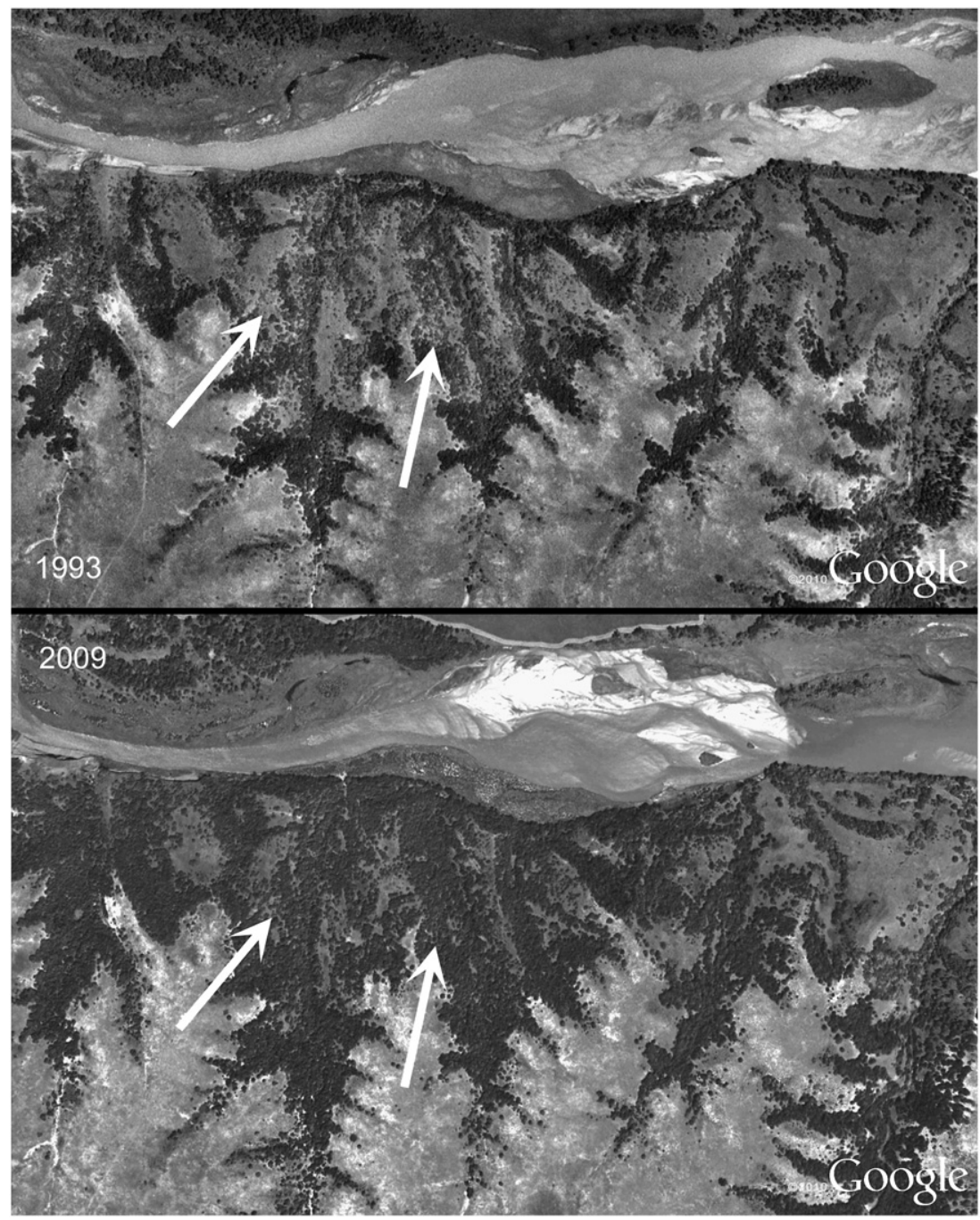

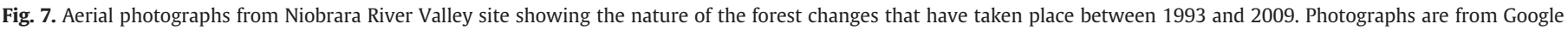
Earth. Arrows denote areas that have shown marked increases in forest cover over the time period.

some of the higher elevation conifer areas in the Wyoming study area showing increasing trends in greenness, which we interpret as meaning that some forests are showing increased trends in forest biomass. We believe that it would be relevant to conduct similar Landsat time series investigations throughout the entire western United States so that we can develop better perspectives on the patterns and locations of changing conifer forest canopy conditions and to assess their relationship with fire.

Also noteworthy was the evidence of trends of increasing canopy cover (decreases in SWIR/NIR) in some of the deciduous forest species, which under normal conditions would be interpreted as "improving" conditions. One such region can be seen in the aspen woodlands in the northwestern part of the study area (blue areas in Fig. 3). Conversely, we also observed evidence for decreasing canopy cover trends (i.e., increases in SWIR/NIR) for a similar amount of deciduous vegetation, which would normally be interpreted as declining conditions. Some of these canopy cover trends are likely related to the aspen die-off that is occurring throughout much of the western US, including parts of the study area. It should be noted that deciduous systems tend to be characterized by higher intra- and inter-annual spectral variability than conifer systems, in part due to phenological cycles. Thus, trend analyses tend to be more difficult for deciduous than conifer ecosystems. We anticipate addressing deciduous forest trends and changes in greater detail in future investigations, which will likely involve incorporation of additional data sets, including both Landsat and MODIS.
We felt that this is beyond the scope of the current investigation, but recognize that this as an important future research topic.

Except when there was evidence of fire disturbance or mining, there were not many patches within the shrubland areas that showed marked evidence of change. This was true for both southwestern US and Wyoming study areas. We did notice some small patches of increasing and decreasing trends in canopy cover, but these appeared to be local rather than regional events. It is very likely that some of these trends are related to shifts in local range management and/or changes in species composition, the latter perhaps related to increases in invasive species. Further investigation of these areas would be necessary in order to explain some of these features. Nonetheless, we did not find evidence for pervasive increases or decreases in sagebrush canopy cover or greenness.

Within the Niobrara Nebraska study, we noted that greenness has increased diffusely throughout the region's forests (Fig. 6). This is consistent with forest growth and expansion throughout the area, and is supported through analysis of the Google Earth aerial photographs. The expansion of forests in this region is a long-term phenomenon, and appears to be occurring not only at the interface between prairie and forest, but is also occurring in the form of increased density of the existing forest canopy. This is in contrast to what we observed in the southwestern US, where we observed little evidence of forest expansion or increased density. Increases in woody vegetation are known to be occurring in many grass-dominated 


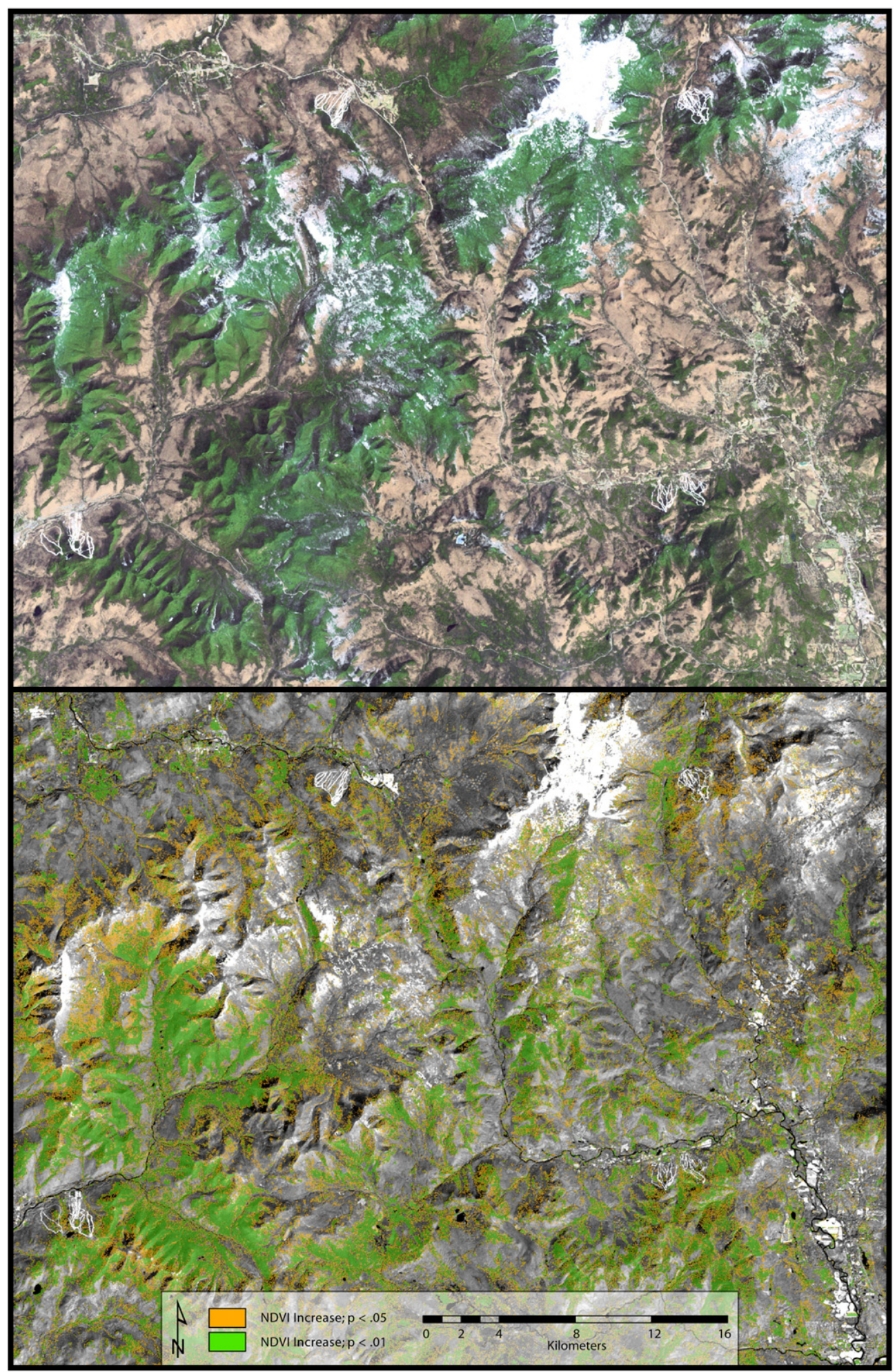

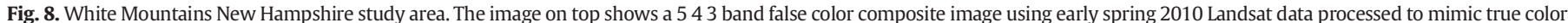

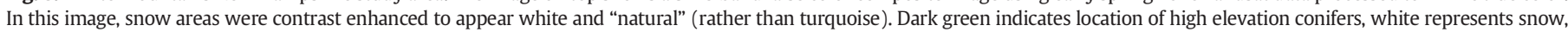

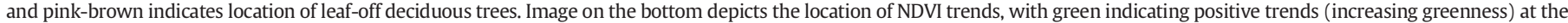
0.01 level of confidence, and orange indicating areas of increasing greenness where $p$ values range between 0.01 and 0.05 .

ecosystems throughout the world (Heisler et al., 2003; Hobbs and Mooney, 1986; Knight et al., 1994), and these increases are generally attributed to changes in land-use practices such as grazing and reductions in fire frequency. In the case of the Niobrara River Valley area, encroachment of eastern red cedar has been documented (Frost and Powell, 2011), and is considered to be a problem affecting wildlife in the region.
Similar forest expansion events are occurring in nearby eastern South Dakota where smaller prairie remnants are being replaced by eastern red cedar (Spencer et al., 2009).

The only other major greenness changes that we noticed within the Niobrara Nebraska region were located in the agricultural areas in association with center pivots. Most of the center pivots that 
showed increasing trends in greenness were actually prairie in the earlier scenes used. Irrigation has been steadily on the rise through the region, as evidenced by the increased number of center pivots during the timeframe of the study (1987-2010). This is typical of much of the northern Great Plains, where a long term historical trend of land conversion from non-irrigated to irrigated agriculture has occurred (Mahmood et al., 2006).

\subsection{Ecological considerations; New Hampshire White Mountains}

We found evidence for increased greenness in the forests of the White Mountains using leaf-off (spring) data, but little such evidence using leaf-on (summer) data. The seasonal discrepancies are attributed to the nature of the forest canopies in the region. Higher elevations throughout the region are typically dominated by balsam fir, and to a lesser extent red spruce. Conifer vegetation is both in the upper story as well as the understory, and what is remotely sensed at these higher elevations is mostly conifer vegetation in both leaf-off and leaf-on conditions. Slightly lower down the mountain, and just below the spruce-fir overstory zone, paper birch constitutes the major portion of the overstory vegetation. The understory vegetation in this zone is often dominated by balsam fir. Thus, for this "middle" zone, the majority of what is remotely-sensed with leaf-on data tends to be deciduous vegetation (paper birch), and what is remotely sensed with leaf-off data is often conifer vegetation (balsam fir). Thus, the trends of increasing greenness detected using leaf-off time series data imply an increase of conifer vegetation, and the locations and timing of this implies an increase in understory balsam fir composition. Close and careful inspection of 1987 with 2010 leaf-off imagery supports this increase of coniferous vegetation at these middle elevations. Unfortunately, there is little field information to corroborate these findings.

The increase of balsam fir in the understory of these mountains is an interesting phenomenon. We do not understand exactly why this is occurring, but we suspect that the birch canopies are getting thinner, which is lowering a natural suppression of growth of the balsam fir in the understory. The balsam fir that is currently in the understory appears to be filling in the space vacated by the thinning of the overstory, and thus we may be detecting a succession-related process. The trend analysis generated using leaf-on data supports this; we noticed evidence of decreased greenness in the middle elevation paper birch canopies in the leaf-on time series data. The explanation as to why the paper birch communities might be undergoing decreases in greenness is open to speculation, but there is evidence from the Green Mountains nearby in Vermont that the paper birch communities are in decline (Breckage et al., 2009). One explanation offered is that the paper birch is being adversely impacted by climate change (Breckage et al., 2009), although other agents such as insects and disease cannot be ruled out. It is also known that paper birch has its range bounded by temperature, and seldom grows naturally where average July temperatures exceed $21{ }^{\circ} \mathrm{C}$ (Burns and Honkala, 1965). It may be relevant that paper birch has been predicted to show diminishing habitat area based on a modeling study of impacts of climate change on individual tree species (Iverson et al., 2007). Another possibility is that the paper birch communities were all established at about the same time, perhaps related to the cessation of certain land-use practices such as logging and use of slash fires 80-110 years ago (Goodale et al., 2000). After establishment, stands of paper birch usually last only one generation and are then replaced by more tolerant species (Burns and Honkala, 1965). Thus, it is possible that the birch trees are all of approximately the same stand age, and are experiencing an age-related dieback. It is also possible that this dieback is being further accelerated by climate factors. Regardless of the specifics, we believe that balsam fir in the paper birch understory is increasing, and is in the process of replacing the paper birch in the overstory.

\subsection{Methodological considerations}

Results from this study indicate that analyses of Landsat time series data provide useful perspectives regarding long-term gradual ecosystem changes taking place across our landscapes. All four areas investigated showed evidence of significant trends in spectral change associated with the gradual loss and accrual of vegetation canopy cover. The approaches used in this paper provide objective assessments of trends taking place throughout differing ecosystems. There is virtually no subjectivity or "hand crafting" involved in the generation of these products. The spatial depictions of the $p$ values provide a sense of the pattern of a given trend, as well as a sense of confidence that the trend is valid. Meanwhile, the regression model slopes provide some measure of the magnitude of the change. Once the analyses are conducted, the challenge is to determine the cause or the meaning of the trend, which often requires input of local knowledge and ancillary data, including field information, existing land-cover data sets, and climate data. It should be noted that the spatial data sets developed in this study, whereby gradual changes are highlighted by pixels showing statistically significant regression trends, imply a certain amount of quantifiable error. We can expect that approximately $5.0 \%$ of the pixels showing trends at 0.05 level of confidence to represent false positive random error. This implies that images showing diffuse "speckling" patterns of pixels at the 0.05 level of confidence may not be indicating real change, at least when the number of significant to non-significant pixels for the region is low (e.g., less than $5.0 \%$ ). Meanwhile, images showing dense clusters of pixels with significant trends have greater likelihood of indicating valid gradual change. One could target the isolated single statistically significant pixels in the zones of diffuse speckling and remove them. This might be particularly warranted if the number of significant to nonsignificant pixels is low (e.g., less than $5.0 \%$ ).

While detection and mapping of statistically significant trends is straightforward, the interpretation often becomes a case-by-case evaluation, and validation of results can be problematic. This has also been recognized as a potential problem by Cohen et al. (2010), who developed an image time series visualization and data collection tool called TimeSync to facilitate interpretations of time series data and trajectories with Google Earth images. In our study, we found that many of the forests in the southwestern US are showing evidence of decreasing canopy cover, and we required other sources of information to help us interpret these changing patterns. Some of the requisite information was readily available, but other times it was not. For instance, a substantial amount of useful data exists about forest insect damage in the western US from the USDA Forest Service. This information is acquired by aerial sketch mapping, and while these data sets are relatively coarse, we found the information to be quite valuable for assessing and interpreting Landsat-derived ecosystem trends. Conversely, there tends to be very limited accessible information describing balsam fir understory vegetation and rangeland status, making evaluations much more difficult in these other ecosystems. We did not find Google Earth data to be particularly useful for these evaluations due to spatial and temporal scale issues.

A second difficulty in conducting these investigations is specifically related to availability of precise field information useful for the quantitative characterization of the trends. We often do not have the field reference information to enable quantification of the trend in a biophysical sense, which is often required for modeling applications. For instance, it is generally difficult to translate gradual changes in Landsat spectral response to quantitative changes in aboveground biomass, which could then be used effectively in carbon modeling studies.

A third issue that can be problematic relates to knowing the precise time interval to focus on when assessing a particular trend. With a Landsat TM/ETM + archive available since 1984, the tendency is to generate trend data over the entire $26+$ year time span. 
However, many ecosystem trends are periodic, with increases in canopy cover followed by decreases in canopy cover, and vice versa. As an example, a forest that has been impacted by insects may decrease in greenness over a period of years, but then as the forest recovers, it might increase in greenness as new plants take the place of the damaged ones. An analysis over the entire time period may result in no statistical linear trend because the greenness increases and decreases cancel each other out. Thus, it is important to identify the time window of interest, which might require some a priori knowledge of the trend of interest. In some cases, it might be best to develop several sets of trends analyses over shorter periods of time. Alternatively, there may be situations when spectral trends are best fit using nonlinear models, including second order fits or various case-specific and user-defined functions of known trajectories (Kennedy et al., 2007). We believe that development of monitoring protocols incorporating a combination of these conditions and approaches would be ideal and represent a valid direction for future work.

And finally, it can be very important that the best and most appropriate image data sets be selected. If one is interested in detecting changes in deciduous forest canopies, it is especially important to analyze data using time periods when the vegetation is as phenologically stable as possible. Similarly, it is important to avoid data sets that have spectral differences caused by short-term inconsequential changes. For instance, for analyzing rangelands, it is important that background conditions among images be comparable. Soil moisture variables can have major impact on reflectance properties (Huete et al., 1985; Todd and Hoffer, 1998), and the inclusion of one or more scenes with differing moisture conditions can have major impacts on final results. Algorithms are now being used to composite multiple images per year to help minimize these and other related problems (Roy et al., 2010).

\section{Conclusions}

We have demonstrated that Landsat time series data are very valuable for deriving broad scale information about the gradual changes taking place across our landscapes. This information would be very difficult to obtain using other approaches, and we believe that spectral trend data sets will provide the research and natural resource management community with information that will be critical for generating better understanding of the nature of the ecosystem changes taking place through time and for making for better management decisions. While it is widely known that gradual landscape changes are pervasive, it is important for the natural resource community to have more specific information regarding these changes. Such analyses should be routinely conducted, and it is not unreasonable to consider doing so operationally at national scales. It should be noted that there are a number of related large area operational mapping and monitoring activities currently underway that use large volumes of Landsat data (e.g., Goward et al., 2008; Homer et al., 2004; Kennedy et al., 2010; Masek et al., 2008; Vogelmann et al., 2011). The type of analyses described in the current investigation represents a potential extension to these other efforts. This is especially feasible now that Landsat data are readily available at no cost, which has effectively removed the major financial barriers that investigators have encountered in the recent past (Woodcock et al., 2008).

\section{Acknowledgments}

The authors would like to acknowledge support from the USGS Landsat Science Team. We would also like to thank personnel of the Department of the Interior, Office of Wildland Fire Coordination, U.S. Forest Service Office of Fire and Aviation Management, and Science and Application Branch of the Center for Earth Resources Observation and Science. We would like to thank Lei Ji for the developing the IMAGINE linear regression model, and Terry Sohl and Chris Barnes for reviews of early drafts of the manuscript. We also thank the four anonymous reviewers of the manuscript for their many excellent comments and suggestions. Any use of trade, firm, or product names is for descriptive purposes only and does not imply endorsement by the U.S. Government.

\section{References}

Beck, P. S. A., Jonsson, P., Hogda, K. A., Karlsen, S. R., Eklundh, L., \& Skidmore, A. K. (2007). A ground-validated NDVI dataset for monitoring vegetation dynamics and mapping phenology in Fennoscandia and the Kola Peninsula. International Journal of Remote Sensing, 28, 4311-4330.

Bloise, S., Domon, G., \& Bouchard, A. (2002). Landscape issues in plant ecology. Ecography, $25,244-256$.

Breckage, B., Osborne, B., Gavin, D. G., Pucko, C., Siccama, T., \& Perkins, T. (2009). A rapid upward shift of a forest ecotone during 40 years of warming in the Green Mountains of Vermont. Proceedings of the National Academy of Sciences, 106, 1479-1483.

Breshears, D. B., Cobb, N. S., Rich, P. M., Price, K. P., Allen, C. D., Balice, R. G., et al. (2005) Regional vegetation die-off in response to global-change-type drought. Proceedings of the National Academy of Sciences, 102, 15144-15148.

Brink, A. B., \& Eva, H. D. (2009). Monitoring 25 years of land cover change dynamics in Africa: A sample based remote sensing approach. Applied Geography, 29, 501-512.

Burns, R. M., \& Honkala, B. H. (1965). Silvics of forest trees of the United States. Handbook 654, Vol. 2, Washington, DC: U.S. Department of Agriculture, Forest Service 877 pp.

Canadell, J., Pataki, D., Gifford, R., Houghton, R., Luo, Y., Raubach, M., et al. (2007). Saturation of the terrestrial carbon sink. Chapter 6 in Terrestrial Ecosystems in a Changing World. Global Change - The IGBP Series, Part A. (pp. 59-78) Berlin: Springer.

Chander, G., Markham, B. L., \& Helder, D. L. (2009). Summary of current radiometric calibration coefficients for Landsat MSS, TM, ETM+, and EO-1 ALI sensors. Remote Sensing of Environment, 113, 893-903.

Clark, J., \& Bobbe, T. (2006). Using remote sensing to map and monitor fire damage in forest ecosystems. In M. A. Wulder, \& S. E. Franklin (Eds.), Understanding forest disturbance and spatial pattern Boca Raton. Florida: CRC Press 246 pp..

Cogbill, C. V., \& White, P. S. (1991). The latitude-elevation relationship for spruce-fir forest and treeline along the Appalachian mountain chain. Plant Ecology, 94, 153-175.

Cohen, W. B., Yang, Z., \& Kennedy, R. (2010). Detecting trends in forest disturbance and recovery using yearly Landsat time series: 2 . TimeSync-tools for calibration and validation. Remote Sensing of Environment, 114, 2911-2924.

Comer, P. D., Faber-Langendoen, D., Evans, R., Gawler, S., Josse, C., Kittel, G., et al. (2003) Ecological systems of the United States: A working classification of U.S. terrestrial systems. Arlington, Virginia: NatureServe.

Cook, E. R., Woodhouse, C. A., Eakin, C. M., Meko, D. M., \& Stahle, D. W. (2004). Long-term aridity changes in the western United States. Science, 306, 1015-1018.

Coppin, P., Jonckheere, I., Nackaerts, K., Muys, B., \& Lambin, E. (2004). Digital change detection methods in ecosystem monitoring: A review. International Journal of Remote Sensing, 25, 1565-1596.

Dale, V. H., Joyce, L. A., McNulty, S., Neilson, R. P., Ayres, M. P., Flannigan, M. D., et al. (2001). Climate change and forest disturbances. BioScience, 51, 723-734.

Fellin, D. G., \& Dewey, J. E. (1982). Western spruce budworm. USDA Forest Service. Forest Insect and Disease Leaflet, 53.

Fisher, J. I., \& Mustard, J. F. (2007). Cross-scalar phenology from ground, Landsat, and MODIS data. Remote Sensing of Environment, 109, 261-273.

Foster, J. R., \& Reiners, W. A. (1983). Vegetation patterns in a virgin subalpine forest at Crawford Notch, White Mountains, New Hampshire. Bulletin of the Torrey Botanical Club, 110, 141-153.

Frost, J. S., \& Powell, L. A. (2011). Cedar infestation impacts avian communities along the Niobrara River Valley, Nebraska. Restoration Ecology, 19, 529-536.

Fuller, D. O., \& Ottke, C. (2002). Land cover, rainfall and land-surface albedo in West Africa. Climatic Change, 54, 181-204.

Ganguly, S., Friedl, M. A., Tan, B., Zhang, X., \& Verma, M. (2010). Land surface phenology from MODIS: Characterization of the collection 5 global land cover dynamics product. Remote Sensing of Environment, 114, 1805-1816.

Gasparri, N. I., Parmudhi, M. G., Bono, J., Karszenbaum, H., \& Montenegro, C. L. (2010) Assessing multi-temporal Landsat 7 ETM + images for estimating above-ground biomass in subtropical dry forests of Argentina. Journal of Arid Environments, 74, $1262-1270$

GEO (2005). The Global Earth Observation System of Systems (GEOSS) - 10-year implementation plan and reference document. Online:. http://earthobservations. org/documents.shtml Accessed February, 2011

Gitlin, A. R., Stultz, C. M., Bowker, M. A., Stumpf, S., Paxton, K. L., Kennedy, K., et al. (2006). Mortality gradients within and among dominant plant populations as barometers of ecosystem change during extreme drought. Conservation Biology, 20, 1477-1486.

Goldblum, D., \& Rigg, L. S. (2010). The deciduous forest-boreal forest ecotone. Geography Compass, 4, 701-717.

Goodale, C. L., Aber, J. D., \& McDowell, W. H. (2000). The long-term effects of disturbance on organic and inorganic nitrogen export in the White Mountains, New Hampshire. Ecosystems, 3, 433-450.

Goward, S. N., Masek, J. G., Cohen, W., Moisen, G., Collatz, G. J., Healey, S., et al. (2008) Forest disturbance and North American carbon flux. EOS, Transactions, 89, 105-107.

Griffith, G. E., \& Omernik, J. M. (2008). Ecoregions of Kansas and Nebraska (EPA). The Encyclopedia of the Earth. http://www.eoearth.org/article/Ecoregions_of_Kansas_ and_Nebraska_(EPA) Accessed June, 2011 
Griffith, G. E., \& Omernik, J. M. (2009). Ecoregions of Wyoming (EPA). The Encyclopedia of the Earth. http://www.eoearth.org/article/Ecoregions_of_Wyoming_(EPA Accessed June, 2011

Hansen, M. C., Roy, D. P., Lindquist, E., Adusei, B., Justice, C. O., \& Alstatt, A. (2008). A method for integrating MODIS and Landsat data for systematic monitoring of forest cover and change in the Congo Basin. Remote Sensing of Environment, 112, 2495-2513.

comps. Hayes, J. L., \& Lundquist, J. E. (2009). The western bark beetle research group: A unique collaboration with forest health protection-Proceedings of a symposium at the 2007 Society of American Foresters conference. General Technical Report PNW-GTR-784.: U.S. Department of Agriculture, Forest Service, Pacific Northwest Research Station $134 \mathrm{pp}$.

Heisler, J. L., Briggs, J. M., \& Knapp, A. K. (2003). Long-term patterns of shrub expansion of a C4-dominated grassland: Fire frequency and the dynamics of shrub cover and abundance. American Journal of Botany, 90, 423-428.

Hepinstall-Cymerman, J., Coe, S., \& Alberti, M. (2009). Using urban landscape trajectories to develop a multi-temporal land cover database to support ecological modeling. Remote Sensing, 1, 1353-1379.

Hobbs, R. J., \& Mooney, H. A. (1986). Community changes following shrub invasion in grasslands. Oecologia, 70, 508-513.

Homer, C., Aldridge, C. L., Meyer, D. K., \& Schell, S. (2012). Multi-scale remote sensing sagebrush characterization with regression trees over Wyoming, USA: laying a foundation for monitoring. International Journal of Applied Earth Observation and Geoinformation, 14, 233-244.

Homer, C., Huang, C., Yang, L., Wylie, B., \& Coan, M. (2004). Development of a 2001 national land-cover database for the United States. Photogrammetric Engineering and Remote Sensing, 70, 829-840.

Houghton, R. A., Hackler, J. L., \& Lawrence, K. T. (2000). Changes in terrestrial carbon storage in the United States. 2: The role of fire and fire management. Global Ecology and Biogeography, 9, 145-170.

Huang, C. Y., Asner, G. P., Barger, N. N., Neff, J. C., \& Floyd, M. L. (2010). Regional aboveground live carbon losses due to drought-induced tree dieback in pinon-juniper ecosystems. Remote Sensing of Environment, 114, 1471-1479.

Huang, C., Goward, S. N., Masek, J. G., Thomas, N., Zhu, Z., \& Vogelmann, J. E. (2010). An automated approach for reconstructing recent forest disturbance history using dense Landsat time series stacks. Remote Sensing of Environment, 114, 183-198.

Huete, A. R., Jackson, R. D., \& Post, D. F. (1985). Spectral response of a plant canopy with different soil backgrounds. Remote Sensing of Environment, 17, 37-53.

Iverson, L., Prasad, A., \& Matthews, S. (2007). Modeling potential climate change impacts on the trees of the northeastern United States. Mitigation and Adaption Strategies for Global Change, 13, 487-516.

Kaul, R. B., Kantak, G. E., \& Churchill, S. P. (1988). The Niobrara River valley. A postglacial migration corridor and refugium of forest plants and animals in the grasslands of central North America. The Botanical Review, 54, 44-81.

Kennedy, R. E., Cohen, W. B., \& Schroeder, T. A. (2007). Trajectory-based change detection for automated characterization of forest disturbance dynamics. Remote Sensing of Environment, 110, 370-386.

Kennedy, R. E., Yang, Z., \& Cohen, W. (2010). Detecting trends in forest disturbance and recovery using yearly Landsat time series: 1 . LandTrendr - Temporal segmentation algorithms. Remote Sensing of Environment, 114, 2897-2910.

Knight, C. L., Briggs, J. M., \& Nellis, M. D. (1994). Expansion of gallery forest on Konza Prairie Research Natural Area, Kansas, USA. Landscape Ecology, 9, 117-125.

Lord, D., Desjardins, R. L., \& Dube, P. A. (1985). Influence of wind on crop canopy reflectance measurements. Remote Sensing of Environment, 18, 113-123.

Lovett, G. M., Canham, C. D., Arther, M. A., Weathers, K. C., \& Fitzhugh, R. D. (2006). Forest ecosystem responses to exotic pests and pathogens in eastern North America. BioScience, 56, 395-405.

Mahmood, R., Foster, S. A., Keeling, T., Hubbard, K. G., Carlson, C., \& Leeper, R. (2006). Impacts of irrigation on 20th century temperature in the northern Great Plains. Global and Planetary Change, 54, 1-18.

Manning, A. D., Fischer, J., Felton, A., Newll, B., Steffen, W., \& Lindenmayer, D. B. (2009) Landscape fluidity - A unifying perspective for understanding and adapting to global change. Journal of Biogeography, 36, 193-199.

Masek, J. G., Huang, C., Wolfe, R., Cohen, W., Hall, F., Kutler, J., et al. (2008). North American forest disturbance mapped from decadal Landsat record. Remote Sensing of Environment, 112, 2914-2926.

Masek, J. G., Vermote, E. F., Saleous, N. E., Wolfe, R., Hall, F. G., Huemmrich, K. F., et al. (2006). A Landsat surface reflectance dataset for North America, 1990-2000. IEEE Geoscience and Remote Sensing Letters, 3, 68-72.

McDonald, R. I., Halpin, P. N., \& Urban, D. L. (2007). Monitoring succession from space: A case study from the North Carolina Piedmont. Applied Vegetation Science, 10, 193-2007.

MTBS (2011). Monitoring trends in burn severity website. http://mtbs.gov Accessed June, 2011

National Drought Mitigation Center (2011). US drought monitor. http://www.drought. unl.edu Accessed June, 2011
Perry, G. L. W., \& Millington, J. D. A. (2007). Spatial modeling of succession-disturbance dynamics in forest ecosystems: Concepts and examples. Perspectives in Plant Ecology, Evolution and Systematics, 9, 191-210.

Reed, B. C., Brown, J. F., Vanderzee, D., Loveland, T. R., Merchant, J. W., \& Ohlen, D. O. (1994). Measuring phenological variability from satellite imagery. Journal of Vegetation Science, 5, 703-714

Roder, A., Udelhoven, T., Hill, J., del Barrio, G., \& Tsiourlis, G. (2008). Trend analysis of Landsat-TM and -ETM + imagery to monitor grazing impact in a rangeland ecosystem in northern Greece. Remote Sensing of Environment, 112, 2863-2875.

Rollins, M. G. (2009). LANDFIRE: A nationally consistent vegetation, wildland fire, and fuel assessment. International Journal of Wildland Fire, 18, 235-249.

Roy, D. P., Ju, J., Kline, K., Scaramuzza, P. L., Kovalskyy, V., Hansen, M., et al. (2010). Web-enabled Landsat data (WELD): Landsat ETM + composited mosaics of the conterminous United States. Remote Sensing of Environment, 114, 35-49.

Schott, J. R., Salvaggio, C., \& Volchok, W. J. (1988). Radiometric scene normalization using pseudoinvariant features. Remote Sensing of Environment, 26, 1-16.

Souza, C. M., \& Roberts, D. (2005). Mapping forest degradation in the Amazon region with Ikonos images. International Journal of Remote Sensing, 26, 425-429.

Spencer, C. N., Matzner, S. L., Smalley, J., Bukrey, M., Onberg, J., Chapman, M., et al. (2009). Forest expansion and soil carbon changes in the Loess Hills of eastern South Dakota. The American Midland Naturalist, 161, 273-285.

Steinauer, E. M., \& Bragg, T. B. (1987). Ponderosa pine (Pinus ponderosa) invasion of Nebraska Sandhills prairie. The American Midland Naturalist, 118, 358-365.

Todd, S. W., \& Hoffer, R. M. (1998). Responses of spectral indices to variations in vegetation cover and soil background. Photogrammetric Engineering and Remote Sensing, 64, 915-921.

Turner, M. G. (2005). Landscape ecology: What is the state of the science? Annual Review of Ecology, Evolution, and Systematics, 36, 319-344.

USDA (2011). United States Department of Agriculture website. http://fhm.fs.fed.us Accessed June, 2011

Verbesselt, J., Hyndman, R., Newnham, G., \& Culvenor, D. (2010). Detecting trend and seasonal changes in satellite image time series. Remote Sensing of Environment, $114,106-115$.

Vogelmann, J. E. (1990). Comparison between two vegetation indices for measuring different types of forest damage in the northeastern United States. International Journal of Remote Sensing, 11, 2281-2297.

Vogelmann, J. E., \& DeFelice, T. (2003). Characterization of intra-annual reflectance properties of land cover classes in southeastern South Dakota using Landsat TM and ETM + data. Canadian Journal of Remote Sensing, 29, 219-229.

Vogelmann, J. E., Kost, J. R., Tolk, B., Howard, S., Short, K., Chen, X., et al. (2011). Monitoring landscape change for LANDFIRE using multi-temporal satellite imagery and ancillary data. IEEE Journal of Selected Topics in Applied Earth Observations and Remote Sensing, 4, 252-264.

Vogelmann, J. E., Tolk, B., \& Zhu, Z. (2009). Monitoring forest changes in the southwestern United States using multitemporal Landsat data. Remote Sensing of Environment, 113, 1739-1748.

White, M. A., De Beurs, K. M., Didan, K., Inouyes, D. W., Richardson, A. D., Jensen, P., et al. (2009). Intercomparison, interpretation, and assessment of spring phenology in North America estimated from remote sensing for 1982-2006. Global Change Biology, 15, 2335-2359.

Woodcock, C. E., Allen, R., Anderson, M., Belward, A., Bindschadler, R., Cohen, W., et al. (2008). Free access to Landsat imagery. Science, 320, 1011.

Worrall, J. J., Egeland, L., Eager, T., Mask, R. A., Johnson, E. W., Kemp, P. A., et al. (2008). Rapid mortality of Populus tremuloides in southwestern Colorado, USA. Forest Ecology and Management, 255, 686-696.

Wulder, M. A., White, J. C., Alvarez, F., Han, T., Rogan, J., \& Hawkes, B. (2009). Characterizing boreal forest wildfire with multi-temporal Landsat and LIDAR data. Remote Sensing of Environment, 113, 1540-1555.

Wulder, M. A., White, J. C., Goward, S. N., Masek, J. G., Irons, J. R., Herold, M., et al. (2008). Landsat continuity: Issues and opportunities for land cover monitoring. Remote Sensing of Environment, 112, 955-969.

Xian, G., \& Homer, C. (2010). Updating the 2001 National Land Cover Database impervious surface products to 2006 using Landsat imagery change detection methods. Remote Sensing of Environment, 114, 1676-1686.

Xian, G., Homer, C., \& Aldridge, C. (2012). Assessing long-term variations in sagebrush habitat - Characterization of spatial extents and distribution patterns using multitemporal satellite remote sensing data. International Journal of Remote Sensing, 33, 2034-2058.

Xian, G., Homer, C., \& Fry, J. (2009). Updating the 2001 National Land Cover database land cover classification to 2006 by using Landsat imagery change detection methods. Remote Sensing of Environment, 113, 1133-1147. 